\title{
Diş hekimliğinde bulk fill kompozit rezinler
}

\author{
Numan Aydın(0000-0001-8628-4507) ${ }^{\alpha}$, Serpil Karaoğlanoğlu(0000-0003-0601-8028) ${ }^{\alpha}$, Elif Aybala Oktay(0000-0003-4716-948X) ${ }^{\alpha}$, \\ Fulya Toksoy Topçu(0000-0003-0730-7710) ${ }^{\alpha}$, Funda Demir(0000-0002-2260-1638) ${ }^{\alpha}$
}

Selcuk Dent J, 2019; 6: 229-238 (Doi: 10.15311/selcukdentj.414591)

Bašvuru Tarihi: 12 Nisan 2018 Yayına Kabul Tarihi: 15 Kasım 2018

\begin{abstract}
Öz
Diş hekimliğinde bulk fill kompozit rezinler

Posterior dişlerin restorasyonunda kullanılan kompozit rezin materyallerin mekanik ve estetik özelliklerinin geliştirilmesi kullanım kolaylığı beklentisini beraberinde getirmiştir. Bu amaçla kullanılan bulk tekniği ve bu teknikle uygulanan kompozit rezin materyaller son yıllarda yaygın olarak kullanılmaktadır. Kompozit rezinlerdeki gelişmelere rağmen bu restorasyonlarda zaman içerisinde oluşan problemler genellikle kompozitlerin polimerizasyon büzülme stresi ile ilişkilendirilir. Polimerizasyon büzülmesini azaltmak amacıyla kompozitlerin inkremental teknik ile (tabakalar hâlinde) uygulanması önerilmektedir. Fakat kompozitlerin inkremental yerleştirmesi derin kavitelerde ışınlama sayısını ve uygulanma süresini artırmaktadır. Yeni nesil bulk fill kompozitler gelişmiş translusent yapı ve farklı fotoaktif başlatıcı içermektedirler. Bu özellikleri nedeniyle geniş kavitelerine daha büyük kütleler hâlinde yerleştirilebilmektedir. Bu kompozitlerin geleneksel kompozitlere göre artan ışınlama derinliği ve polimerizasyon büzülme stresini azaltılması, restoratif diş hekimliğinde heyecan uyandıran bir yenilik olmuştur. Bu derlememizin amacl; yeni nesil bulk fill kompozitleri ticari örnekleri ile analiz ederek, bu kompozitlerin özellikleri, avantajları ve kullanımları hakkında bir literatür incelemesi sunmaktır.
\end{abstract}

\section{ANAHTAR KELIMELER}

Bulk fill kompozit, kompozit rezin, polimerizasyon büzülmesi

Diş hekimliğinde kullanılan restoratif materyallerdeki gelişmeler, amalgam ile restore edilen geniş posterior kavitelerde kompozit rezinlerin kullanımına olanak sağlamıştır. ${ }^{1}$ Posterior dişlerin restorasyonunda kullanılan kompozit rezin materyallerin mekanik ve estetik özelliklerinin geliştirilmesi de kullanım kolaylığı beklentisini beraberinde getirmiştir. Bu amaçla ön plana çıkan bulk tekniği (tek tabaka) ve bu teknikle uygulanan kompozit rezin materyaller son zamanlarda oldukça popüler olmuştur.

Bowen tarafından 1960'lı yıllarda ilk rezin esaslı kompozitlerin tanıtılmasından sonra, üreticiler bu restoratif materyallerin fiziksel ve mekanik özelliklerinin geliştirilmesi için çalışmaktadırlar. ${ }^{2-3}$ Kompozit rezinlerdeki gelişmelere rağmen bu restorasyonlarda zaman içerisinde oluşan marjinal renklenme ve kenar uyumsuzlukları, tüberkül fraktürleri, mikrosızıntı,

\section{ABSTRACT}

Bulk fill composite resins in dentistry

The improvement of the mechanical and aesthetic properties of composite resin materials used in the restoration of posterior teeth led to the expectation of ease of use. Bulk technique used for this purpose and composite resin materials applied with this technique have been widely used in recent years. Despite the improvements in composite resins, the problems that arise over time in these restorations are often related to the polymerization shrinkage stress of composites. It is suggested to apply composites by incremental layering technique in order to decrease polymerisation shrinkage. Incremental placement of composites, however, increases the number of irradiation and application time in deep cavities. The new generation of bulk fill composites contain advanced translucent structure and different photoactive initiators. Because of these properties, they can be placed in larger quantities to the dental cavities. Increased depth of irradiation and reduction of polymerization shrinkage stress of these composites compared to traditional composites has been an exciting innovation in restorative dentistry. The purpose of this compilation is; to examination a literature review on the properties, advantages and uses of these composites by analyzing the new generation bulk fill composites with commercial examples.

\section{KEYWORDS}

Bulk fill composite, composite resin, polymerization shrinkage

tekrarlayan çürükler ve restorasyon sonrası hassasiyet gibi olumsuz sonuçlar genellikle kompozitlerin polimerizasyon büzülme stresi ile ilişkilendirilir. ${ }^{4-7}$

Kompozit rezinlerin polimerizasyonu boyunca monomerlerin polimere dönüşüm miktarı konversiyon ya da polimerizasyon derecesi olarak adlandırlır. ${ }^{8}$ Uygulanan ışık gücü ve süresi polimerizasyon derecesini etkileyerek kompozitin yapısında büzülmeye neden olmaktadır. Polimerizasyon büzülmesini azaltmak amacıyla kompozitlerin inkremental teknikle (tabakalar hâlinde) uygulanması önerilmektedir. Fakat kompozitlerin inkremental yerleştirmesi derin kavitelerde ışınlama sayısını ve uygulama süresini artırmaktadır. Kompozitlerin kaviteye daha büyük kütlelerde ve daha fazla kalınlıkta uygulanabilmesini sağlamak amacıyla son yıllarda "bulk fill" kompozitler geliştirilmiştir. ${ }^{9,10}$ Yeni nesil bulk

${ }^{\alpha}$ Sağlık Bilimleri Üniversitesi Gülhane Diş Hekimliği Fakültesi Restoratif Diş Tedavisi Anabilim Dalı, Ankara 
$\begin{array}{lcr}\text { fill kompozitler } & \begin{array}{r}\text { gelişmiş } \\ \text { dolayı }\end{array} & \begin{array}{r}\text { translusent } \\ \text { geleneksel }\end{array} \\ \text { komplarından } & \text { daha } & \text { yüksek }\end{array}$ $\begin{array}{lrl}\text { kompozitlerden } & \text { daha } & \text { yüksek } \\ \text { polimerizasyon derecesine } & \text { sahiptir. Bu }\end{array}$ kompozitlerin polimerizasyon derecesinin artması, kaviteye daha büyük kütleler hâlinde yerleştirilebilmelerine olanak sağlamaktadır. ${ }^{11,12}$ Ayrıca bulk fill kompozitler geleneksel kompozitlere göre daha düşük viskoziteye sahipken, akışkan kompozitler ile kıyaslandığında ise daha düşük polimerizasyon büzülmesi gösterirler. ${ }^{13}$

Bulk fill kompozit rezinlerin en büyük avantajı 4-6 mm kalınlıkta, bulk (tek tabaka) halinde yerleştirilebilmeleri sayesinde klinik çalışma süresinin kısalması ve düşük polimerizasyon büzülmesi göstermeleridir. Diğer avantajları ise, hekime uygulama kolaylığı sağlaması, kompozit tabakasının adaptasyonunun daha iyi sağlanarak tabakalar arasında boşluk oluşmaması, çiğneme kuvvetlerine karşı aşınma direncinin iyi olması, yeterli radyoopasite, yüzey özellikleri ve renk uyumunun klinik olarak kabul edilebilir seviyede olmasıdır. ${ }^{14}$

$\mathrm{Bu}$ derlemenin amacı; piyasada mevcut olan bulk-fill kompozitleri analiz ederek, sınıflandırılması, özellikleri, avantajları, klinik performansı ve toksisitesi hakkında bir literatür incelemesi sunmaktır.

\section{A. Bulk-fill kompozitlerin sınıflandırılması}

Bulk fill kompozit rezinler yoğunluklarına ve polimerizasyon şekillerine göre sınıflandırılırlar. Yoğunluklarına göre; düşük ve yüksek viskoziteli olarak 2 gruba ayrılırlar (Tablo 1). Düşük viskoziteli olanlar, akışkan bulk fill kompozit rezinler olarak da adlandırılmaktadır. ${ }^{15} \mathrm{Bu}$ kompozitlerin esneme kapasitesinin yüksek olması ve fotoaktif grup olarak üretan dimetakrilat rezin içeriği nedeniyle posterior dişlere açılan kavitelerde, polimerizasyon büzülme streslerini azaltmak amacıyla liner olarak kullanılmaktadır. ${ }^{16}$ Fakat düşük viskoziteli bulk fill kompozit rezinlerin; yüzey sertlikleri daha düşük, su emilimi daha yüksek ve mekanik özelliklerinin yetersizdir. $\mathrm{Bu}$ nedenle üzerlerinin $2 \mathrm{~mm}$ kalınlığında geleneksel tipte bir kompozit rezinle örtülmesi tavsiye edilmektedir. ${ }^{17}$
Tablo 1.

Günümüzde mevcut olan bulk fill kompozitlerin sınıflandırılması

\begin{tabular}{|c|c|c|c|c|}
\hline & Bulk fill kompozit & $\begin{array}{l}\text { Bulk fill base } \\
\text { kompozit }\end{array}$ & $\begin{array}{l}\text { Sonic- } \\
\text { active } \\
\text { olan bulk } \\
\text { fill } \\
\text { kompozit }\end{array}$ & $\begin{array}{l}\text { Dual } \\
\text { serleşen } \\
\text { bulk fill } \\
\text { kompozit }\end{array}$ \\
\hline \multirow[t]{5}{*}{$\begin{array}{l}\text { Bulk fill } \\
\text { kompozitler }\end{array}$} & $\begin{array}{l}\text { Filtek Bulk Fill } \\
\text { Posterior Restoratif } \\
\text { (3M ESPE, ABD) }\end{array}$ & $\begin{array}{l}\text { SDR (Dentsply, } \\
\text { ABD) }\end{array}$ & $\begin{array}{l}\text { SonicFill } 2 \\
\text { (Kerr,ABD) }\end{array}$ & $\begin{array}{l}\text { Fill Up } \\
\text { (Coltene, } \\
\text { İsvicre) }\end{array}$ \\
\hline & $\begin{array}{l}\text { Tetric EvoCeram } \\
\text { Bulk Fill (Ivoclar } \\
\text { Vivadent, } \\
\text { Lihtenştayn) }\end{array}$ & $\begin{array}{l}\text { Filtek Bulk Fill } \\
\text { Flowable (3M } \\
\text { ESPE, ABD) } \\
\text { Venus Bulk Fill } \\
\text { (Heraeus Kulzer, } \\
\text { Almanya) }\end{array}$ & & $\begin{array}{l}\text { HyperFil } \\
\text { (Parkell, } \\
\text { ABD) }\end{array}$ \\
\hline & 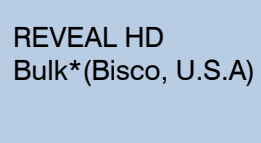 & $\begin{array}{l}\text { Tetric Evo Flow } \\
\text { Bulk Fill (Ivoclar } \\
\text { Vivadent, } \\
\text { Lihtenştayn) }\end{array}$ & & \\
\hline & $\begin{array}{l}\text { GrandioSO x-tra } \\
\text { (Voco, Almanya) }\end{array}$ & $\begin{array}{l}\text { X-tra base } \\
\text { (Voco,Almanya) }\end{array}$ & & \\
\hline & $\begin{array}{l}\text { Estelite Bulk Fill } \\
\text { flow* * (Tokuyama, } \\
\text { Japonya) }\end{array}$ & $\begin{array}{l}\text { Parkell LC base } \\
\text { Bulk Fill (Parkell, } \\
\text { ABD) }\end{array}$ & & \\
\hline Vizkositesi & Yüksek & Düşük & $\begin{array}{l}2 \text { fazlı } \\
\text { (yüksek- } \\
\text { az) }\end{array}$ & Orta \\
\hline $\begin{array}{l}\text { Polimerizasyon } \\
\text { derinliği }\end{array}$ & $4 \mathrm{~mm}$ & $4 \mathrm{~mm}^{*}$ & $5 \mathrm{~mm}$ & Yok \\
\hline $\begin{array}{l}\text { Geleneksel } \\
\text { kompozit ile } \\
\text { kapatma }\end{array}$ & Yok & Var & Yok & Yok \\
\hline
\end{tabular}

Yüksek viskoziteli bulk fill kompozitlerin rezin matriks içerisinde daha fazla doldurucu içerirler. Doldurucu oranının artması kompozitin mekanik özelliklerini artırarak posterior kavitelerde tek başına kullanılabilmelerini sağlamıştır. Diğer yüksek viskoziteli kompozitlerden farklı olarak, sonic olarak aktive edilen Sonic Fill 2 (Kerr) kompozit, özel dizayn edilen el aleti ve sonik titreşim ile yüksek viskoziteden düşük viskoziteli kompozite dönüşür. Dolayısıyla daha akıcı kıvamda olan kompozit kaviteye daha kolay uygulanabilir. ${ }^{15}$

Bu kompozitler polimerizasyon yöntemlerine göre ise; kimyasal, ışık ve dual sertleşen şeklinde sınıflandırıır. Işık ile polimerize olan bulk fill kompozitler geleneksel kompozitler gibi 420-470 nm dalga boyunda aktive olmaktadır. ${ }^{19} \mathrm{Bu}$ kompozitler için üreticiler farklı ışınlama süresi ve polimerizasyon derinliği önermektedirler. Piyasada iki adet dual sertleşen bulk fill kompozit dolgu bulunmaktadır. Bu kompozitler hem kimyasal hem de ışık ile polimerize olur. Restorasyonun polimerizasyonu ışık ile başlatılır ve ışığın ulaşamayacağı en derin noktalar zaman içerisinde kimyasal olarak polimerize olur. Bu özelliklerinden dolayı dual sertleşen bulk fill kompozitler tek bir yerleştirmede $10 \mathrm{~mm}+$ kadar kullanılabilirler. ${ }^{15}$ 


\section{B. Bulk-fill kompozitlerin yapısı}

Bulk fill kompozitlerin kimyasal yapıları temelde geleneksel kompozitlere benzerlik göstermektedir. Diş hekimliğinde kullanılan kompozit rezinler organik faz (polimer matriksi), inorganik faz (doldurucu fazı) ve bağlayıcı faz (ara faz) olarak adlandırılan üç farklı fazdan oluşur. ${ }^{18} \mathrm{Bu}$ kompozitler geleneksel kompozitler ile benzer doldurucu içerseler de, bazı bulk fill kompozit üreticileri polimer matriks içerisindeki bisphenol A glysidyl methacrylate (BisGMA)'ı kullanmaktan vazgeçmişler ve diğer dimetakrilatlardan oluşan organik matriks tercih etmeye başlamışlardır. ${ }^{19}$ $\mathrm{Bu}$ durum rezin matriks içerisindeki UDMA, TEGDMA ve etoksile EBPDMA'nın Bis-GMA'ya göre daha esnek bir polimer yapı oluşturmasını ve daha az viskoz olmasını sağlamıştır. Ayrıca Bis-GMA EBPDMA'ya göre daha fazla hidrofilik olduğu ve su emerek bozulma riski taşıması nedeni ile bulk fill kompozitlerde EBPDMA'nın kullanılması renk değişikliği riskini azaltmaktadır. ${ }^{20-21}$

Bulk fill kompozitlerde polimerizasyon derinliğini artırmak için kompozit rezinlerin translüsensisini artırma ve rezin matriks içerisinde farklı fotoaktif başlatıcılar kullanımı tercih edilmektedir. SDR (Dentsply) fotoaktif gruplara sahip UDMA monomeri içermektedir. Bu fotoaktif gruplar monomerin polimerizasyon büzülme stresini kontrol altına alarak kompozitin $4 \mathrm{~mm}$ derinliğe kadar polimerize olmasını sağlamaktadır. ${ }^{19}$ Tetric EvoCeram (Ivoclar Vivadent) bulk fill kompozitin yapısında ise "Ivocerin" adı verilen madde bulunmakta ve bu madde polimerizasyon başlatıcı sistemleri hızlandırarak materyalin daha kalın tabakalarda polimerize olmasını sağlamaktadır. ${ }^{22}$ Bulk fill kompozitler rezin matriks içerisinde farklı oranlarda doldurucu içermektedir (Tablo 2).
Tablo 2.

\section{Bulk fill kompozitlerin doldurucu oranı ve içerikleri}

\begin{tabular}{|c|c|c|c|}
\hline Bulk Fill kompozitler & $\begin{array}{l}\text { Doldurucu } \\
\text { oranı }\end{array}$ & $\begin{array}{l}\text { Doldurucu } \\
\text { tipi }\end{array}$ & Matriks tipi \\
\hline $\begin{array}{l}\text { Filtek Bulk Fill } \\
\text { Posterior Restorativ } \\
\text { (3M ESPE, ABD) }\end{array}$ & $\begin{array}{l}\text { Agırlık \% 76,5 } \\
\text { Hacim \% 58,4 }\end{array}$ & $\begin{array}{l}\text { Zirkona/Silica } \\
\text { Ytterbiyum } \\
\text { trifloride }\end{array}$ & $\begin{array}{l}\text { Modifiye UDMA, } \\
\text { TEGDMA, } \\
\text { EBPDMA }\end{array}$ \\
\hline $\begin{array}{l}\text { Filtek Bulk-Fill Flow } \\
\text { (3M ESPE,ABD) }\end{array}$ & $\begin{array}{l}\text { Agırlık \% 64,5 } \\
\text { Hacim \% 42,5 }\end{array}$ & $\begin{array}{l}\text { Zirkona/Silica } \\
\text { Ytterbiyum } \\
\text { trifloride }\end{array}$ & $\begin{array}{l}\text { Bis GMA, UDMA, } \\
\text { Bis EMA ve } \\
\text { Procrylat }\end{array}$ \\
\hline SDR(Dentsply,ABD) & $\begin{array}{l}\text { Agırlık \% } 68 \\
\text { Hacim \% } 44\end{array}$ & $\begin{array}{l}\text { Ba-Al-F - B - } \\
\text { Si-cam, St-Al } \\
-\mathrm{F}-\text { Si-cam }\end{array}$ & $\begin{array}{l}\text { Modifiye UDMA, } \\
\text { TEGDMA, } \\
\text { EBPDMAEBPDMA }\end{array}$ \\
\hline $\begin{array}{l}\text { Venus Bulk Fill } \\
\text { (Heraeus } \\
\text { Kulzer,Almanya) }\end{array}$ & $\begin{array}{l}\text { Agırlık \% } 65 \\
\text { Hacim \% } 38\end{array}$ & $\begin{array}{l}\mathrm{Ba}-\mathrm{Al}-\mathrm{F}-\mathrm{Si}- \\
\text { cam ve } \mathrm{SiO}_{2} \\
\text { ve } \mathrm{YbF}_{3}\end{array}$ & $\begin{array}{l}\text { UDMA ve } \\
\text { EBPDMA }\end{array}$ \\
\hline $\begin{array}{l}\text { Tetric EvoCeram Bulk } \\
\text { Fill (Ivoclar-Vivadent, } \\
\text { Schaan, Liechtenstein }\end{array}$ & $\begin{array}{l}\text { Agırlık \% 76-77 } \\
\text { Hacim \% 53-54 }\end{array}$ & $\begin{array}{l}\text { Barium cam, } \\
\text { ytterbium } \\
\text { trifluoride, } \\
\text { mixed oxide }\end{array}$ & $\begin{array}{l}\text { Bis-GMA, Bis-EMA } \\
\text { ve UDMA }\end{array}$ \\
\hline $\begin{array}{l}\text { Tetric Evo Flow Bulk } \\
\text { Fill (Ivoclar-Vivadent, } \\
\text { Schaan, Liechtenstein }\end{array}$ & $\begin{array}{l}\text { Agırlık \% 68,2 } \\
\text { Hacim \% 46,4 }\end{array}$ & $\begin{array}{l}\text { Barium cam, } \\
\text { ytterbium } \\
\text { trifluoride, } \\
\text { mixed oxide }\end{array}$ & $\begin{array}{l}\text { Bis-GMA, Bis-EMA } \\
\text { ve UDMA }\end{array}$ \\
\hline SonicFill 2 (Kerr,ABD) & Agırlık \% 83,5 & $\begin{array}{l}\text { Silicon } \\
\text { dioxide,barium } \\
\text { cam }\end{array}$ & $\begin{array}{l}\text { Bis-GMA, } \\
\text { TEGDMA, Bis- } \\
\text { EMA }\end{array}$ \\
\hline $\begin{array}{l}\text { X-tra base } \\
\text { (Voco,Almanya) }\end{array}$ & Agırlık \% 75 & $\begin{array}{l}\text { Barium- } \\
\text { boron- } \\
\text { alumino- } \\
\text { silicate cam }\end{array}$ & $\begin{array}{l}\text { Bis-GMA, UDMA, } \\
\text { TEGDMA }\end{array}$ \\
\hline $\begin{array}{l}\text { GrandioSO X-tra } \\
\text { (Voco,Almanya) }\end{array}$ & Agırlık \% 86 & - & - \\
\hline $\begin{array}{l}\text { Estelite Bulk Fill } \\
\text { Flow* } \\
\text { (Tokuyama,Japonya) }\end{array}$ & $\begin{array}{l}\text { Agırlık \% } 70 \\
\text { Hacim \% } 56\end{array}$ & $\begin{array}{l}\text { Silika-zirkonya } \\
\text { ve kompozit } \\
\text { dolgu }\end{array}$ & $\begin{array}{l}\text { Bis-GMA, } \\
\text { TEGDMA, Bis- } \\
\text { MPEPP }\end{array}$ \\
\hline $\begin{array}{l}\text { Parkell LC base Bulk } \\
\text { Fill (Parkell,ABD) }\end{array}$ & Agırlık \% 70 & $\begin{array}{l}\text { İnorganik } \\
\text { doldurucu }\end{array}$ & $\begin{array}{l}\text { BisMPEPP,UDMA, } \\
\text { polyglycol } \\
\text { diacrylate, }\end{array}$ \\
\hline
\end{tabular}

*Bis-GMA; Bisfenol-A diglisidil dimetakrilat, EBPDMA; Etoksilated bisfenol-A-dimetakrilat, TEGDMA; Trietilen glikol dimetakrilat, UDMA; Üretan dimetakrilat, Bis-EMA; Etoksilated bisfenol-A-dimetakrilat

\section{Mekanik özelikler}

\section{Polimerizasyonun derecesi}

Polimerizasyon kompozitlerin içerisindeki monomerlerin polimer zincire dönüşmesini sağlayarak restorasyonun fiziksel, mekanik özellikleri ve klinik başarısını direkt etkilemektedir. Polimerizasyonun derecesi kompozit rezinlerin koyuluk ve saydamlığına göre farklılık gösterirken, opak olanların polimerizasyonun derecesi daha azdır. ${ }^{23}$ Üreticiler bulk fill kompozitlerin ışınlama derinliğini artırmak için çeşitli yöntemler geliştirmişlerdir. Bu yöntemler; dolgu maddesi içeriğinin azaltılması ${ }^{24}$, dolgu maddesi parçacık boyutunun arttırımas ${ }^{24}$, ek foto başlatıcıların kullanılmasıdır. ${ }^{22}$ 
Pek çok bulk fill kompozit rezinde doldurucu partiküllerin boyutları büyütülerek doldurucu matriks ara yüzeyi azaltılmıştır. Bu sayede ışık saçılımı azaltılarak, kompozit rezinin polimerizasyonu daha iyi sağlanmaktadır. Bazı üreticiler polimerizasyon derinliğini artırmak için kompozit rezinlerin translüsensisini artırma veya rezin matriks içerisinde farklı fotoaktif başlatıcılar ${ }^{21-22}$ kullanmışlardır. Bunun için en basit yöntem translusent doldurucu partiküllerin oranını artırmaktır. ${ }^{24}$ İçerdikleri, yiterbiyum triflorid, baryum alüminyum silikat cam, zirkonyum silika partiküller sayesinde translusentlikleri artarak ışık cihazının polimerize edici etkisinin daha derinlere ulaşması sağlanmaktadır. ${ }^{25}$ Işık ile aktive olan bulk fill kompozitlerin ışınlama derinlikleri 4-6 $\mathrm{mm}$ arasındadır (Tablo 3).

Tablo 3.

\section{Üreticilerin önerdiği polimerizasyon süresi}

\begin{tabular}{|c|c|c|c|}
\hline \multirow{2}{*}{$\begin{array}{l}\text { Işıkla sertleşen bulk } \\
\text { fill kompozitler }\end{array}$} & \multirow{2}{*}{$\begin{array}{l}\text { Maksimum } \\
\text { tabaka } \\
\text { kalınlığı }\end{array}$} & \multicolumn{2}{|c|}{ Önerilen ışık süresi- saniye (sn) } \\
\hline & & $\begin{array}{l}\text { Minimum yoğunluk } \\
550 \mathrm{~mW} / \mathrm{cm}^{2}\end{array}$ & $\begin{array}{l}1000+\mathrm{mW} / \mathrm{cm}^{2} \\
\text { Yoğunluk }\end{array}$ \\
\hline $\begin{array}{l}\text { Filtek Bulk Fill } \\
\text { Posterior Restorativ } \\
\text { (3M ESPE, ABD) }\end{array}$ & $\begin{array}{l}4 \mathrm{~mm} \text { (Class } \\
\mathrm{I}, \mathrm{III}, \mathrm{IV}, \mathrm{V}) \\
5 \mathrm{~mm} \text { (Class } \\
\text { II) }\end{array}$ & $\begin{array}{l}\text { Class I,III,IV,V }(4 \mathrm{~mm}) \\
\text { i. } 40 \mathrm{sn} \text {. Class II ( } 5 \\
\mathrm{~mm}): 20 \mathrm{sn} .\end{array}$ & $\begin{array}{l}\text { Class I,III,IV, V }(4 \\
\mathrm{mm}) \text { i. } 20 \mathrm{sn} . \text { Class II } \\
(5 \mathrm{~mm}): 20 \mathrm{sn} .\end{array}$ \\
\hline $\begin{array}{l}\text { Filtek Bulk-Fill Flow } \\
\text { (3M ESPE, ABD) }\end{array}$ & $4 \mathrm{~mm}$ & $\begin{array}{l}\text { Universal renk: } 20 \text { sn. } \\
\text { Renk } A 1, A 2, A 3: 40 \\
\text { sn. }\end{array}$ & $\begin{array}{l}\text { Universal renk: } 10 \text { sn. } \\
\text { Renk } A 1, A 2, A 3: 20 \\
\text { sn. }\end{array}$ \\
\hline $\begin{array}{l}\text { SDR(Dentsply, } \\
\text { ABD) }\end{array}$ & $4 \mathrm{~mm}$ & i. $20 \mathrm{sn}$. & - \\
\hline $\begin{array}{l}\text { Venus Bulk Fill } \\
\text { (Heraeus Kulzer, } \\
\text { Almanya) }\end{array}$ & $4 \mathrm{~mm}$ & i. $20 \mathrm{sn}$. & - \\
\hline $\begin{array}{l}\text { Tetric EvoCeram } \\
\text { Bulk Fill (Ivoclar } \\
\text { Vivadent, } \\
\text { Lihtenştayn) }\end{array}$ & $4 \mathrm{~mm}$ & i. $20 \mathrm{sn}$. & i. $10 \mathrm{sn}$. \\
\hline $\begin{array}{l}\text { Tetric Evo Flow } \\
\text { Bulk Fill (Ivoclar } \\
\text { Vivadent, } \\
\text { Lihtenştayn) }\end{array}$ & $4 \mathrm{~mm}$ & i. $20 \mathrm{sn}$. & i. $10 \mathrm{sn}$. \\
\hline $\begin{array}{l}\text { SonicFill } 2 \text { (Kerr, } \\
\text { ABD) }\end{array}$ & $5 \mathrm{~mm}$ & $\begin{array}{l}\text { i. } 20 \mathrm{sn} .{ }^{*} \text { Minimum } \\
\text { güç: } 650 \mathrm{~mW} / \mathrm{cm}^{2}\end{array}$ & $10 \mathrm{sn}$. \\
\hline $\begin{array}{l}\text { X-tra base (Voco, } \\
\text { Almanya) }\end{array}$ & $4 \mathrm{~mm}$ & $\begin{array}{l}\text { Universal renk: } 10 \mathrm{sn} \text {. } \\
\text { A2 renk: } 40 \mathrm{sn} .\end{array}$ & $\begin{array}{l}\text { Universal renk: } 10 \mathrm{sn} \text {. } \\
\text { A2 renk: } 20 \mathrm{sn} .\end{array}$ \\
\hline $\begin{array}{l}\text { REVEAL HD Bulk } \\
\text { (Bisco, USA) }\end{array}$ & $5-6 \mathrm{~mm}$ & i. $40 \mathrm{sn}$. & i. $20 \mathrm{sn}$. \\
\hline $\begin{array}{l}\text { GrandioSO x-tra } \\
\text { (Voco, Almanya) }\end{array}$ & & $\begin{array}{l}\text { Universal renk: } 20 \text { sn. } \\
\text { Renk A1, A2, A3: } 40 \\
\text { sn. }\end{array}$ & $\begin{array}{l}\text { Universal renk: } 10 \text { sn. } \\
\text { Renk } A 1, A 2, A 3: 20 \\
\text { sn. }\end{array}$ \\
\hline $\begin{array}{l}\text { Estelite Bulk Fill } \\
\text { Flow (Tokuyama, } \\
\text { Japonya) }\end{array}$ & $4 \mathrm{~mm}$ & $\begin{array}{l}\text { i. } 10 \mathrm{~s} \text { *Minimum güç: } \\
\geq 800 \mathrm{~mW} / \mathrm{cm}^{2}\end{array}$ & - \\
\hline $\begin{array}{l}\text { Parkell LC base } \\
\text { Bulk Fill (Parkell, } \\
\text { ABD) }\end{array}$ & $4 \mathrm{~mm}$ & $\begin{array}{l}\text { i. } 10 \mathrm{sn} .{ }^{*} \text { Minimum } \\
\text { güç: } \geq 600 \mathrm{~mW} / \mathrm{cm}^{2}\end{array}$ & - \\
\hline
\end{tabular}


Bulk fill kompozitlerin geleneksel kompozitlere göre artan ışınlama derinliği kompozitler için heyecan veren bir yenilik olmuştur.

\section{Polimerizasyon büzülme stresi}

Kompozit rezinlerdeki gelişmelere rağmen en önemli dezavantajlarından biri, monomerlerin polimer zincire dönüşmesi sırasında hacimsel olarak \% $1,5-3$ oranında büzülme görülmesidir. ${ }^{31}$ Polimerizasyon büzülmesinin; kavitenin boyutu, konfigürasyon faktörü (c faktör), uygulama tekniği, uygulanan ışığın pozisyonu, ışığın gücü ve süresi, kavite taban materyallerinin kullanımı, kompozitin elastisite modülü gibi birçok etkeni bulunmaktadır. ${ }^{32}$ Kompozitlerin kaviteye yerleştirilirken birden fazla duvara temas etmesi $C$ faktörünün artmasına neden olur. $C$ faktörünü artması büzülme stresini artırarak diş ile restorasyon arasında en zayıf yerden restorasyonun başarısızlığına neden olur. ${ }^{33}$ Büzülme stresine bağlı başarısızlıklar; sekonder çürük, marjinal renklenme, diş fraktürü ve post operatif hassasiyet görülmesidir.

El-Damanhoury ve ark. ${ }^{14}$ bulk fill kompozitlerin polimerizasyon stresi üzerine yaptıkları çalışmalarında; üreticilerin iddialarını destekler şekilde bulk fill kompozitlerin geleneksel kompozitlerden daha düşük polimerizasyon stresi sergilediğini ifade etmişlerdir. Jung ve ark. ${ }^{34}$ da yaptıkları çalışmalarında bulk fill kompozitlerin daha düşük polimerizasyon büzülme gerilimi göstererek marjinal kenarda daha az polimerizasyon büzülme stresi oluşturacağını bildirmişlerdir. Chesterman ve ark. ${ }^{15}$ yaptıkları derlemede bulk fill kompozitlerin geleneksel kompozitlerden daha düşük polimerizasyon stresi gösterdiğini belirtmişlerdir. Kompozitlerin içerisine daha düşük elastisite modülüne sahip büzülme stres azaltıcıların katılması ile polimerizasyon stresinin azaltılması sağlanmıştır. ${ }^{35}$

\section{Marjinal kenar adaptasyonu}

Marjinal kenar adaptasyonunun yetersizliği, kompozit rezin restorasyonlarda mikrosızıntıya neden olan en temel dezavantajlarından biridir. ${ }^{36}$ Mikrosızıntıyı önlemek için güncel yaklaşım olarak akışkan bulk fill kompozitler ortaya çıkmıştır. ${ }^{17}$ Bulk fill kompozitlerin düşük polimerizasyon büzülmesi göstermesi sayesinde marjinal aralık oluşumu gibi problemleri minimalize ettiğ ${ }^{37,10}$ düşük viskositeleri sayesinde kavite duvarlarına daha iyi adaptasyon sağladığı tespit edilmiştir. ${ }^{25}$

Scotti ve ark. ${ }^{38}$ akıcı bulk fill kompozitin mikrosızıntı seviyelerini karşılaştırdıkları çalışmalarında, mine kenarlarında en düşük mikrosızıntı değerini nanohibrit tipte kompozit rezinin gösterdiğini söylerken, dentin kenarlarında ise en düşük mikrosızıntı değerlerini bulk fill kompozitin kullanıldığı grubun gösterdiğini bildirmişlerdir.
Moorthy ve ark. ${ }^{39}$ ise kaide olarak akışkan bulk fill kompozit kullanılmasının, sınıf II kavitelerde servikal mikrosızıntıya etkisini inceledikleri çalışmalarında, bu kompozitlerin mikrosızıntının azaltılması üzerinde olumlu etki oluşturmadığını tespit etmişlerdir. Webber ve ark. $^{40}$ da yaptıkları çalışmalarında bulk fill kompozitlerin mikrosızıntıya etkisini farklı bir nanohibrit kompozit kullanarak karşılaştırmışlar ve bulk fill kompozitlerin mikrosızıntıyı azaltmada olumlu bir etki göstermediğini ifade etmişlerdir. Uzel ve ark. ${ }^{41}$ ise bulk fill kompozitler ile ilgili yaptıkları çalışmada kompozitlerin tek tabaka halinde ve tabakalama tekniği ile kullanımında mikrosızıntı yönünden aralarında istatistiksel olarak anlamlı fark bulamamışlardır.

Marjinal kenar adaptasyonu ile ilgili çeşitli görüşler vardır. Bazı literatürlerde geleneksel kompozitler ile bulk fil kompozitler arasında istatiksel olarak anlamlı bir fark bulunamazken ${ }^{37,42,43}$, bazı literatürler bulk fil kompozitlerin geleneksel kompozitlerden daha iyi olduğunu bildirmişlerdir. ${ }^{34,44}$ Ayrıca yüksek viskoziteli bulk fil kompozitlerin daha büyük marjinal aralık oluşturduğu bulunmuştur. ${ }^{45}$ Yüksek viskoziteli bulk fill kompozitlerdeki bu problemi önlemek için yerleştirmeden önce kavite tabanına düşük viskoziteli kompozit kullanılması önerilmiştir. ${ }^{45}$

Tomaszewska ve ark. ${ }^{43}$ geleneksel ve bulk fill kompozitlerin tüberkül fraktürleri ve servikal mikrosızıntı üzerine etkilerini değerlendirdikleri çalışmalarında bulk fill kompozitlerin servikal mikrosızıntıyı azaltırken, tüberkül kırıklarını önlemediğini ifade etmişlerdir. Dual sertleşen bulk fil kompozitlerin ise marjinal adapdasyonlarının kabul edilebilir seviyede olduğu bildirilmiştir. ${ }^{46}$

Yapılan çalışmalarda kavite derinlikleri aynı olan geleneksel ve bulk fill kompozit ile restore edilen dişler kenar adaptasyonu yönünden karşılaştırımasında aralarında anlamlı fark bulunamamışıı. ${ }^{37,42}$ Güncel olarak piyasaya sürülen bulk-fill kompozitlerin de minesement birleşiminin altında sonlanan kavitelerde 4 mm'lik tek kütle halinde uygulanmasının olumsuz etki yaratmadığı tespit edilmiştir. ${ }^{43}$ Stres azaltıcı rezin içeren akıcı bulk fill kompozitlerin uygun vakalarda minesement birleşiminin altında sonlanan kavitelerde tercih edilebileceği bildirilmiştir.

\section{Fiziksel özellikleri}

Kompozitlerin posterior dişlerde kullanılması mekanik özelliklerin geliştirilmesi ile gerçekleşmiştir. Üreticiler geleneksel kompozitlerin geliştirilmesinde mekanik özelliklerini iyileştirmek için doldurucu miktarını artırmışlardır. Fakat bulk fill kompozitlerin polimerizasyon erinliğini artırmak için daha düşük doldurucu kullanmışlardır.

Sonik fil 2 (Kerr) (\%83.5), Evoceram bulk fill (Ivoclar Vivadent) (\%79-81) ve SDR (Dentsply) \% 68) kompozitlere göre yüksek doldurucu içermesi 
içermesi nedeniyle daha iyi bükülme ve basma direncine sahiptir. Doldurucu oranı az olan bulk fill kompozitlerin üzerini ağız ortamındaki fiziksel ve kimyasal etkilerden korumak için geleneksel kompozitler ile kaplamak gerekir. ${ }^{47}$ Fakat dual sertleşen bulk fill kompozitlerin doldurucu oranlarının düşük olmasına rağmen (\%65) üreticiler bu kompozitin üzerini geleneksel bir kompozit ile kaplamaya gerek olmadığını ifade etmişlerdir. ${ }^{15}$ Akman ve ark. ${ }^{48}$ yaptıkları araştırmada bulk fill kompozitler ile geleneksel kompozit materyaller arasında su emilim ve çözünürlük değerleri açısından istatistiksel olarak fark gözlenmediğini ifade etmişlerdir.

Engelhardt ve ark. ${ }^{49}$ bulk fill akıcı kompozitlerin geleneksel akıcı kompozitlere göre daha düşük kırılma ve aşınma direnci olduğunu saptamışlardır. Leprince prince ve ark. $^{50}$ yaptıkları çalışmalarında bulk fill kompozitlerin geleneksel kompozitlere göre düşük mekanik özellik gösterdiği belirmişlerdir.

Monterubbianesi ve ark. ${ }^{51}$ bulk fill kompozitlerin spektroskopik ve mekanik özelliklerini inceledikleri çalışmalarında, düşük ve yüksek viskoziteli bulk fill kompozitlerin yeterli polimerizasyon gerçekleştirdiği ve VHN (Vickers mikosetlik) değerleri karşılaştırıldığında en düşük değeri SDR (Dentsply) kompozit gösterirken, en yüksek sertlik değerini SonicFill 2 (Keer) bulk fill kompozitin gösterdiğini bildirmişlerdir. Bucuta ve ark. ${ }^{52}$ yaptıkları çalışmalarında ışınlama derinliğinin kompozitlerin saydamlığına bağlı olduğunu ve düşük viskoziteli bulk fillı kompozitlerin düşük mekanik özellik gösterdiğini belirtmişlerdir. Tauböcka ve ark. ${ }^{53}$ düşük viskoziteli bulk fill kompozitlerin polimerizasyonu için 20 sn ışınlama süresinin yeterli olduğunu ve daha fazla polimerizasyon süresinin bulk fill kompozitlerin mekanik özelliklerini etkilemediğini saptamışlardır. Karadaş ve ark. $^{21}$ termal siklus yöntemi yöntemiyle yaşlandırma işleminin düşük ve yüksek viskoziteli bulk fill kompozitlerin yüzey pürüzlülüğünü önemli ölçüde artırırken, geleneksel kompozitlerin (nano hibrit) yüzeyinde önemli bir değişiklik oluşturmadığını belirtmişlerdir. Bulk fill ve nano-hibrit kompozitler, polisaj sonrası nano seramik ve mikro-hibrit kompozitler ile karşılaştırıldığında en yumuşak yüzeyi sergilemektedirler. ${ }^{54}$

\section{Bulk fill kompozitlerin klinik performansı}

Bulk fil kompozitlerle ilgili klinik çalışmalar kısıtlı olmasına rağmen, bu kompozitlerin amalgam veya geleneksel kompozitlere karşı uygun bir alternatif olduğunu gösteren çalışmalar vardır. ${ }^{55-57}$ Van Dijken ve ark. ${ }^{55}$ yaptıkları klinik çalışmada tabakalı teknikle yerleştirilen geneleksek bir kompozit ile bulk fill kompozitin karşılaştırılmasında, bulk fill kompozitlerin yıllara göre kıyaslanabilir bir klinik başarı sağladığını bildirmişlerdir. Bayraktar ve ark. ${ }^{56}$ yaptıkları klinik çalışmada bulk fill kompozitlerin posterior kompozit ile benzer klinik performans gösterdiğini söylemişlerdir. Karaman ve ark. ${ }^{57}$ kanal tedavisi görmüş dişlerde yaptıkları 3 yıllık in vivo çalışmada kavite taban maddesi olarak geleneksel akıcı veya bulk fill akıcı kompozit kullandıkları ve üst restorasyonunu geleneksel kompozit (GrandioSO, Voco) ile tedavi ettikleri dişlerde retansiyon, marjinal renklenme,marjinal adaptasyon,renk uyumu, yüzey uyumu, anatomik form ve sekonder çürük açısından istatiksel olarak anlamlı bir fark bulamamışlardır.

Yazıcı ve ark. ${ }^{58}$ bulk fill kompozit rezin ile yaptıkları 3 yıllık klinik takip çalışmasında, Tetric EvoCeram (Ivoclar Vivadent) bulk fillin, kenar renklenmesi ve kenar uyumu açısından iyi klinik performans gösterdiği sonucuna varmışlardır. Burke ve ark. ${ }^{59}$ bulk fill kompozitlerin arka grup dişlerde kullanımını değerlendirdikleri çalışmalarında postoperatif duyarlıık oluşmadığını ifade etmişlerdir. Bulk fil kompozitlerin geleneksel kompozitlere göre renk ve transtlüsensi kısıtlı olsa da geleneksel kompozitlerle birlikte kullanılabilir olmaları avantajdır.

\section{E. Bulk fill kompozitlerin toksisitesi}

Kompozit rezinlerin günümüzde yaygın ve uzun süre başarılı kullanılmasına rağmen toksisiteleri ile ilgili endişeler mevcuttur. Çiğneme kuvvetlerinin ve kimyasal bozulmanın etkisiyle kompozit restorsyonlardan salınan zararlı maddeler pulpa ve tükürük yolu ile kan dolaşımına karışarak toksik ve genetoksik etki oluşturabilir.

Kompozit rezinlerden salınan zararlı monomerler reaksiyona girmemiş monomerle doğru orantılıdır. ${ }^{60}$ Kompozit rezinlerin polimerizasyonu sırasında reaksiyona giren monomer oranını artırmak için düşük moleküler ağırlıklı monomerler, 2-hidroksietil metakrilat (HEMA) ve trietilen glikol dimetakrilat (TEGDMA) kullanılır. ${ }^{61,62}$ Fakat bu monomerlerin, hücre yapılarında reaktif oksijen radikallerinin (ROS) neden olduğu hasara karşı koruyan doğal radikal tutucu glutatyon (GSH) düzeylerini düşürdüğü saptamışlardır. ${ }^{63,64}$ Oluşan oksidatif stres DNA'da zincir kırılmasına neden olabileceğini belirtmişlerdir. ${ }^{63,64}$

Kompozit materyallerde sıklıkla kullanılan bisfenolA-glisidildimetakrilat (Bis-GMA), mikronükleik ve DNA iplikçiklerinin sayısını arttırarak, doza bağımlı genotoksisite göstermiştir. ${ }^{65,66}$ Kleinsasseret ve ark. ${ }^{65}$ Bis-GMA'nın insan lenfositleri üzerine etkilerini inceledikleri in vivo çalışmada bu materyallerin DNA göçünü arttırdığını, Bis-GMA'nın HEMA, TEGDMA veya UDMA'dan daha genotoksik olduğunu ortaya çıkarmışlardır.

Toh ve ark. ${ }^{67}$ bulk fill kompozitler ile yaptıkları çalışmada kompozitlerin kimyasal bileşim, numune kalınlığı ve ekstraktların test konsantrasyonlarının 
hücre canlıı̆ı ve morfolojisi üzerinde önemli etkilere sahip olduğunu ve tüm bulk fill kompozitlerin üreticilerin kullanım talimatlarına göre hazırlanmasına rağmen $4 \mathrm{~mm}$ kalınlığında yüksek hücre canlılığını (>\% 70) göstermediğini belirtmiştirler. Tauböcka ve ark. ${ }^{53}$ akıcı bulk fill kompozitler ile ilgili yaptıkları çalışmada bulk fill materyallerin alt ve üst yüzeyinden elde edilen parçacıkların genotoksik etkileri indüklemediğini ve bunun kompozitlerin $4 \mathrm{~mm}$ kalınlıkta uygulandığında yeterli polimerizasyonunun gerçekleşmesi ile açıklandığını ifade etmiştirler.

\section{SONUÇ}

Bulk fill kompozitler ile daha az teknik hassasiyet ve daha kısa sürede diş renginde restorasyonlar yapılabilir. Mekanik özellikleri, yerleştirme tekniği ve estetik özellikleri malzemeler arasında farklıık gösterir. Bu kompozitlerin polimerizasyon derinlikleri ile ilgili üreticilerin iddialarını doğrulayan ve destekleyen in vitro çalışmalar vardır. Arka gurup dişlerdeki geniş kavitelerin restorasyonunda kullanıması diş üzerinde daha az polimerizasyon stresi oluşturur. Düşük viskoziteli bulk fill kompozitler geleneksel kompozitlerin altına stres kırıcı kavite taban maddesi olarak etkin bir şekilde kullanılabilirler. Tedavi süresinin kısa tutulduğu çocuk ve endişeli hastalarda kullanım prosedürleri etkindir. Bu malzemelerin uzun vadeli sonuçları hakkında yeterli klinik çalışma literatürde yoktur. Uzun süreli klinik başarıları ile ilgili çalışmalar yapılana kadar kullanıcılar bulk fill kompozitlerin seçiminde dikkatli davranmalı ve üreticilerin talimatlarına göre uygulamalıdır. 


\section{KAYNAKLAR}

1. A.P.P. Fugolin, C.S. Pfeifer New Resins for Dental Composites Journal of Dental Research 2017;96(10) $1085-1091$

2. Sarret DC, Brooks CN, Rose JT. Clinical performance evaluation of a packable posterior composite in bulkcured restorations. J Am Dent Assoc. 2006; 137: 7180.

3. Eick JD, Welch FH. Polimerization shrinkage of posterior composite resins and its possible influence on postoperative sensivity. Quintessence Int. 1986; 17: 103-11.

4. Irie M, Suzuki K, Watts DC. Marginal gap formation of light-activated restorative materials: effects of immediate setting shrinkage and bond strength. Dent Mater. 2002; 18: 203-10.

5. Sakaguchi RL, Peters MC, Nelson SR, Douglas WH, Poort HW. Effects of polymerization contraction in composite restorations. J Dent. 1992; 20: 178-82.

6. Ferracane JL. Buonocore Lecture: placing dental composites - a stressful experience. Oper Dent. 2008; 33: 247-57.

7. Ferracane JL, Mitchem JC. Relationship between composite contraction stres and leakage in Class V cavities. Am J Dent. 2003; 16: 239-43.

8. Dewaele M, Truffier-Boutry D, Devaux J, Leloup G. Volume contraction in photocured dental resins: the shrinkage-conversion relationship revisited. Dent Mater 2006; 22(4): 359-65.

9. Karaman E, Yazici AR, Ozgunaltay G, Dayangac B. Clinical evaluation of a nanohybrid and a flowable resin composite in non-carious cervical lesions: 24month results. J Adhes Dent 2012; 14(5): 485-92.

10.Donadio-Moura J, Gouw-Soares S, de Freitas PM, Navarro RS, Powell LG, Eduardo Cde P. Tensile bond strength of a flowable composite resin to ER: YAGlaser-treated dentin. Lasers Surg Med 2005; 36(5): 351-5.

11.Rueggeberg F. Contemporary issues in photocuring. Compend Contin Educ Dent Suppl 1999(25): S4-15.

12.Garcia D, Yaman P, Dennison J, Neiva GF. Polymerization shrinkage and depth of cure of bulk fill flowable composite resins. Oper Dent 2014; 39(4): 441-48.

13.Czasch $\mathrm{P}$, llie $\mathrm{N}$. In vitro comparison of mechanical properties and degree of cure of bulk fill composites. Clin Oral Investig 2013; 17(1): 227-35.

14.El-Damanhoury $\mathrm{H}$, Platt $\mathrm{J}$ Polymerization shrinkage stress kinetics and related properties of bulk-fill resin composites. Oper Dent 2014; 39(4): 374-82.

15. Chesterman J, Jowett A, Gallacher A, Nixon P. Bulk-fill resin-based composite restorative materials: a review British Dental Journal 2017; 222: 337-44

16.Garcia D, Yaman P, Dennison J, Neiva G. Polymerization shrinkage and depth of cure of bulk fill flowable composite resins. Oper Dent 2014; 39(4): 441-8.
17. Burgess J, Cakir D. Comparative properties of low-shrinkage composite resins. Compend Contin Educ Dent 2010;31 Spec No 2: 10-5.

18.Dayangaç B, Kompozit rezin restorasyonlar, Quintessence Yayincilik, 2011.

19.Zaruba M, Wegehaupt FJ, Attin T. Comparison between different flow application techniques: SDR vs flowable composite. J Adhes Dent 2013;15(2): 115-21.

20.Sideridou I, Tserki V, Papanastasiou G Effect of chemical structure on degree of conversion in light-cured dimethacrylatebased dental resins. Biomaterials 2002; 23: 1819-29

21.Karadaş $M$, Demirbuğa $S$ Evaluation of Color Stability andSurface Roughness of Bulk-Fill Resin Composites and Nanocomposites Meandros Med Dent J 2017; 18: 199-205

22.Tetric EvoCeram Bulk Fill: The bulk composite without compromises. Scientific Documentation Schaan, Liechtenstein: Ivoclar Vivadent 2011; 1-20.

23.Park J, Chang J, Ferracane J, Lee I B. How should composite be layered to reduce shrinkage stress: incremental or bulk filling? Dent Mater 2008; 24(11): 1501-5.

24.Lee YK. Influence of filler on the difference between the transmitted and reflected colors of experimental resin composites. Dent Mater 2008; 24(9): 1243-7.

25.llie N, Bucuta S, Draenert M. Bulk-fill Resinbased composites: an in vitro assessment of their mechanical performance. Op Dent 2013; 38: 618-25.

26. Rueggeberg F A, Caughman W F, Curtis Jr J W, Davis H C. Factors affecting cure at depths within light-activated resin composites. Am J Dent 1993; 6: 91-5.

27.Tarle Z, Attin T, Marovic D, Andermatt L, Ristic $M$, Taubock T T. Influence of irradiation time on subsurface degree of conversion and microhardness of high-viscosity bulk-fill resin composites. Clin Oral Investig 2014; 19: 83140.

28. Reis AF, Vestphal M, Amaral RC, Rodrigues JA, Roulet JF, Roscoe MG. Efficiency of polymerization of bulkfill composite resins: a systematic review. Braz Oral Res 2017; 31 (suppl): e59.

29.Jung JH, Park SH, Hwang IN. Polymerization shrinkage and depth of cure of bulk-fill resin composites and highly filled flowable resin. Oper Dent 2015; 40(2): 172-80.

30. Flury S, Hayoz S, Peutzfeldt A, Hüsler J, Lussi A. Depth of cure of resin composites: is the ISO 4049 method suitable for bulk fill materials? Dent Mater 2012; 28(5): 521-8. 
31.Yap A.U.J., Senevirante C. Influence of light energy density on effectiveness of composite resin. Oper Dent. 2001; 26: 460-6.

32. ÖImez A, Tuna D Polimerizasyon Büzülmesine Etki Eden Faktörler Cumhuriyet Üniversitesi Diş hekimliği Fakültesi Dergisi 2002; 5(1): 52-7.

33. Feilzer A J, DeGee A J, Davidson C L. Setting stress in composite resin in relation to configuration of the restoration. J Dent Res 1987; 66: 1636-9.

34.Jung JH, Park SH Comparison of Polymerization Shrinkage, Physical Properties, and Marginal Adaptation of Flowable and Restorative Bulk Fill Resin-Based Composites. Oper Dent. 2017; 42(4): 375-86.

35. Isufi A, Plotino G, Grande N M et al. Fracture resistance of endodontically treated teeth restored with a bulkfill flowable material and a resin composite. Annali di stromatologia 2016; 7: 4-10.

36. Altun C. Restoratif Diş Hekimliğinde Mikrosızıntı. Gülhane Tıp Derg. 2005; 47: 77-82.

37.37. Furness A, Tadros MY, Looney SW, Rueggeberg FA. Effect of bulk/incremental fill on internal gap formation of bulk-fill composites. J Dent. 2014; 42: 439-49.

38. Scotti N, Comba A, Gambio A, Paolino DS, Alovisi M, Pasqualini D, Berutti E. Microleakage at enamel and dentin margins with a bulk fills flowable resin. European J Dent. 2014; 8: 1-8.

39. Moorthy A, Hogg $\mathrm{CH}$, Dowling $\mathrm{AH}$, Gruffery BF, Benetti AR, Fleming GJP. Cuspal deflection andflowable resin-based composite base materials. J Dent. 2012; 40: 500-5.

40.40. Webber MBF, Marin GC, Progiante PS, Lolli LF, Marson FC. Bulk-fill resin-based composites: Microleakage of Class II restorations. JSCD 2014; 2: 15-9.

41. Uzel I, Kuru R, Eden E. The Effect of Different Application Procedures on Microleakage and Microhardness of a Bulk-Fill Composite Material EÜ Dişhek Fak Derg 2017; 38(1): 48-53.

42. Campos E A, Ardu S, Leferer D, Jasse E F, Bartolotto T, Krejci I. Marginal adaptation of class II cavities restored with bulk-fill composites. J Dent 2014; 42: 571-81.

43. Tomaszewska I M, Kearns J O, llie N, Fleming G J P. Bulk fill restorative: To cap or not to cap - That is the question? J Dent 2015; 43(3): 309-16.

44. Orlowski M, Tarczydlo B, Chalas R B Renata C. Evaluation of marginal integrity of four bulk-fill dental composite materials: In vitro study. Sci World J 2015; 1-7.

45. Agarwal R S, Hiremath H, Agarwal J, Garg A. Evaluation of cervical marginal and internal adaptation using newer bulk fill Composites: An in vitro study. J Conserv Dent 2015; 18: 56-61.
46. Bahillo J, Bortolotto T, Roig M, Krejci I. Bulk filling of class II cavities with a dual-cure composite: Effect of curing mode and enamel etching on marginal adaptation. J Clin Exp Dent 2014; 6: 502-8.

47.Didem A, Yalcin G. Comparative Mechanical Properties of Bulk-Fill Resins. Open J Comp Mat 2014; 4: 117-21.

48.Akman H, Tosun G, Kahvecioğlu F. Evaluation of water absorption and water solubility properties of bulk-fill restorative materials Selcuk Dent J. 2018; 5: 13-21

49. Engelhardt F, Hahnel S, Preis V, Rosentritt M. Comparison of flowable bulk-fill and flowable resin-based composites: an in vitro analysis. Clin Oral Invest 2016; 20: 2123-30.

50.Prince J G, Palin W M, Vanacker J, Sabbagh J, Devaux J, LeLoup G. Physico-mechanical characteristics of commercially available bulk-fill composites. J Dent 2014; 42: 993-1000.

51.Monterubbianesi R, Orsini G, Tosi G, Conti C,Librando V, Procaccini M, et al. Spectroscopic and Mechanical Properties of a New Generation of Bulk Fill Composites. Front Physiol 2016; 27; 7: 652.

52. Bucuta S, llie N Light transmittance and micromechanical properties of bulk fill vs. conventional resin based composites. Clin Oral Investig. 2014 ; 18(8): 1991-2000.

53.Tauböcka TT, Marovicb D, Zeljezicc D, Steingrubera AD, Attina T, Tarle Z. Genotoxic potential ofdental bulk-fill resin composites Dent Mater. 2017; 33: 788-95

54.Magdy NM, Kola MZ, Alqahtani $\mathrm{HH}$, Alqahtani MD, Alghmlas AS Evaluation of Surface Roughness of Different Direct Resin-based Composites. J Int Soc Prev Community Dent. 2017; 7(3): 104-9.

55.Van Dijken J W, Pallesen U. Posterior bulk-filled resin composite restorations: A 5year randomised controlled clinical study. J Dent 2016; 51: 29-35.

56. Bayraktar Y, Ercan E, Hamidi M M, Colak H. One-year clinical evaluation of different types of bulk-fill composites. J Invest Clin Dent 2016; 0: 1-9.

57. Karaman E, Keskin B, Inan U. Three-year clinical evaluation of class II posterior composite restorations placed with different techniques and flowable composite linings in endodontically treated teeth. Clin Oral Invest 2016; 19: 1-8.

58. Yazıcı AR, Antonson SA, Kutuk ZB, Ergin E. Thirty-Six-Month Clinical Comparison of Bulk Fill and Nanofill Composite Restorations. Oper Dent 2017; 42(5): 478-85. 
59.Burke FJT, Crisp RJ, Panchal D, Redfearn P, Sands P. A Practice-Based Clinical Evaluation of a Bulk Fill Restorative Material. Eur J Prosthodont Restor Dent. 2016; 24(3): 152-7.

60.Wegehaupt FJ, Tauböck TT, Attin T, Belibasakis GN. Influenceof light-curing mode on the cytotoxicity of resin-basedsurface sealants. BMC Oral Health 2014; 14(1): 1-7.

61.Peutzfeldt A. Resin composites in dentistry: the monomersystems. Eur J Oral Sci 1997; 105: 97116.

62.Chen $\mathrm{MH}$. Update on dental nanocomposites. J Dent Res 2010; 89: 549-60.

63. Lee DH, Lim BS, Lee YK, Ahn SJ, Yang HC. Involvement ofoxidative stress in mutagenicity and apoptosis caused bydental resin monomers in cell cultures. Dent Mater 2006; 22: 1086-92.

64.Schweikl H, Spagnuolo G, Schmalz G. Genetic and cellulartoxicology of dental resin monomers. J Dent Res 2006; 85: 870-7.

65. Kleinsasser NH, Wallner BC, Harreus UA, Kleinjung T,Folwaczny M, Hickel R, et al. Genotoxicity and cytotoxicity ofdental materials in human lymphocytes as assessed by thesingle cell microgel electrophoresis (comet) assay. J Dent 2004; 32: 229-34.

66. Li YC, Kuan YH, Huang FM, Chang YC. The role of DNAdamage and caspase activation in cytotoxicity andgenotoxicity of macrophages induced bybisphenol-A-glycidyldimethacrylate. Int Endod J 2012; 45: 499-507.

67.Toh WS, Yap A, Lim SY. In vitro biocompatibility ofcontemporary bulk-fill composites. Oper Dent 2015; 40: 644-52.

Yazışma Adresi:

Numan AYDIN

Sağlık Bilimleri Üniversitesi

Gülhane Diş Hekimliği Fakültesi

Restoratif Diş Tedavisi AD, Ankara

Tel : : +905537323106

E-mail : dt_numan@hotmail.com 